\title{
Influence of Alumina Precursors on Microstructure and Creep Behavior of Sol-Gel Derived Mullite Ceramics
}

\author{
H. Ivankovic ${ }^{1}$, E.Tkalcec ${ }^{1}$, R. Rein ${ }^{2}$ and H. Schmidt ${ }^{2}$ \\ ${ }^{1}$ Faculty of Chemical Engineering and Technology, University of Zagreb, Marulicev trg 19, HR- \\ 10000 Zagreb, Croatia \\ ${ }^{2}$ Institut fuer Neue Materialien, D-66123 Saarbruecken, Germany
}

Keywords: mullite, sintering, 4-point bending creep, sol-gel

\begin{abstract}
The effect of alumina precursors on microstructure, sintering and creep behavior of solgel derived mullite ceramics was studied by scanning and transmission electron microscopy (SEM, TEM and HRTEM), dilatometry and measuring the creep resistance in 4-point bending mode. When aluminum nitrate nonahydrate was used as a precursor, elongated crystals (with longer axis about 5-7 $\mu \mathrm{m}$ ) were embedded into a matrix of polyhedral much smaller grains. This morphology was due to overlapping of mullite crystallization and viscous flow sintering. Equiaxial mullite grains with $1.3 \mu \mathrm{m}$ mean sizes were obtained using boehmite $(\gamma-\mathrm{AlOOH})$ as alumina precursor. Transient alumina formed in situ by the decomposition of boehmite shifted the mullite formation above the sintering temperature, and allowed the formation of equiaxial mullite grains. Four-point bending creep behavior of mullite ceramics was studied in the temperature range of $1320-1400^{\circ} \mathrm{C}$ under the stresses between 40 and $160 \mathrm{MPa}$. The higher creep rate and the smaller activation energy $(\mathrm{Q}=606 \pm 33 \mathrm{~kJ} / \mathrm{mol})$ exhibited the sample with bimodally distributed grain sizes, whereas a smaller creep rate and the higher activation energy $(Q=743 \pm 18 \mathrm{~kJ} / \mathrm{mol})$ were obtained for mullite ceramic with monomodally distributed grain sizes.
\end{abstract}

\section{Introduction}

Mullite is a promising candidate for advanced structural and functional ceramics because of its good thermo-mechanical properties, excellent creep resistance and good chemical and oxidation resistance [1]. Creep of mullite has been investigated for the last three decades. Works have been performed in bending, in compression and in tension [2-6]. Materials with different microstructures and compositions ranging from 67 to $82 \mathrm{wt} \%$ of alumina and a wide range of activation energies (Q 357-1051 kJ/mol), stress exponents ( $\mathrm{n} \sim 0.2-2.7)$ and grain size exponents (p 1-3.7) have been characterized in experiments from 0.2 to $300 \mathrm{MPa}$ and temperatures from 1100 to $1500^{\circ} \mathrm{C}$. There is no universally accepted opinion about the mechanism of the creep. In general, grain boundary sliding (GBS) is considered to be the main deformation mechanism, but some authors suggest that the strain rates are controlled by viscous flow of amorphous grain boundary phases and the others by pure diffusion. It is generally agreed that broad range of reported creep parameters are due to differences in experimental conditions: - loading arrangement, temperature and stress - as well as in the microstructure and composition of the studied materials.

The aim of this work was to correlate the sintering behavior and the bending creep results of two sol-gel derived mullite ceramics with the same stoichiometric 3:2 composition but with different microstructure, morphology and different size and distribution of mullite grains, which was attained by using various alumina precursors. Tetraetoxysilane (TEOS) was used as a source of silica, and aluminum nitrate nonahydrate $\left(\mathrm{Al}\left(\mathrm{NO}_{3}\right)_{3} \cdot 9 \mathrm{H}_{2} \mathrm{O}\right)$ and boehmite $(\gamma-\mathrm{AlOOH})$, respectively, were used as the sources of alumina component.

\section{Experimental Procedure}

Gel $(P B M)$ was prepared by dissolving $\mathrm{Al}\left(\mathrm{NO}_{3}\right)_{3} \cdot 9 \mathrm{H}_{2} \mathrm{O}$ in water. The solution was stirred and refluxed at $60^{\circ} \mathrm{C}$ overnight. Stoichiometric amount of $1 \mathrm{M}$ TEOS in ethanol was dropwise added to nitrate solution. The stirring was continued for next $12 \mathrm{~h}$ whereupon the mixture was brought to $\mathrm{pH}$ 6 by adding $2 \mathrm{M}$ aqueous ammonia. Gel $(B M)$ was synthesized using $\gamma$-AlOOH, boehmite, (,Disperal“ Condea Chemie, mean particle size 30-40 nm, BET $188 \mathrm{~m}^{2} / \mathrm{g}$ ) previously peptized with 
$\mathrm{HNO}_{3}$. The suspension was stirred and refluxed for $24 \mathrm{~h}$ at $60^{\circ} \mathrm{C}$. Stoichiometric amount of $1 \mathrm{M}$ TEOS in ethanol was dropwise added and gelation was carried out by refluxion at $60^{\circ} \mathrm{C}$ during next five days. The prepared gels were further dried at $110^{\circ} \mathrm{C}$ for 72 hours and calcined at $700^{\circ} \mathrm{C}$ for $9 \mathrm{~h}$ to decompose organics and to remove volatiles. Calcined gels were wet ball milled in isopropanol using $\mathrm{ZrO}_{2}$ balls as milling media for $6 \mathrm{~h}$. After milling and drying of the precursor powders, rodlike green bodies performed by cold isostatic pressing were sintered at $1600^{\circ} \mathrm{C}$ for $2 \mathrm{~h}$. Polished and thermally etched surfaces $\left(1500^{\circ} \mathrm{C}, 45 \mathrm{~min}\right)$ of sintered materials were analyzed by scanning ${ }^{\circ}$ and high-resolving transmission electron microscopy (SEM, JEOL, JSM 6400F; HRTEM, CM 200 FEG Philips), and the average grain size was determined by the linear intercept method. The creep resistance was measured in 4-point bending strength mode (spans 20 and $40 \mathrm{~mm}$ ) using polished samples with dimensions $3 \times 4 \times 45 \mathrm{~mm}^{3}$. The measurements were carried out at different stresses from 40 to $160 \mathrm{MPa}$ at the constant temperature $\mathrm{T}=1400^{\circ} \mathrm{C}$, and at the constant stress of $100 \mathrm{MPa}$ from 1320 up to $1420^{\circ} \mathrm{C}$. The experiment data were characterized in terms of steady state creep rate according to the equation:

$$
\varepsilon^{*}=A \cdot \sigma^{n} \cdot \frac{1}{d^{p}} \cdot \exp \left(\frac{-Q}{R T}\right)
$$

$\varepsilon^{*}$ is the steady-state creep rate in $\mathrm{s}^{-1}, \sigma$ is the stress in $\mathrm{MPa}, Q$ is the activation energy for creep deformation; $n$ is stress exponent, $d$ is grain size, $p$ is the grain size exponent, and $A$ is a material constant, which depends on microstructure. $T$ is the absolute temperature and $R$ is the universal gas constant.

\section{Results and Discussion}

Depending on the starting materials and the methods applied, the synthesized precursors have different properties, which in turn affect the resulting properties of the ceramics. Both gels have the

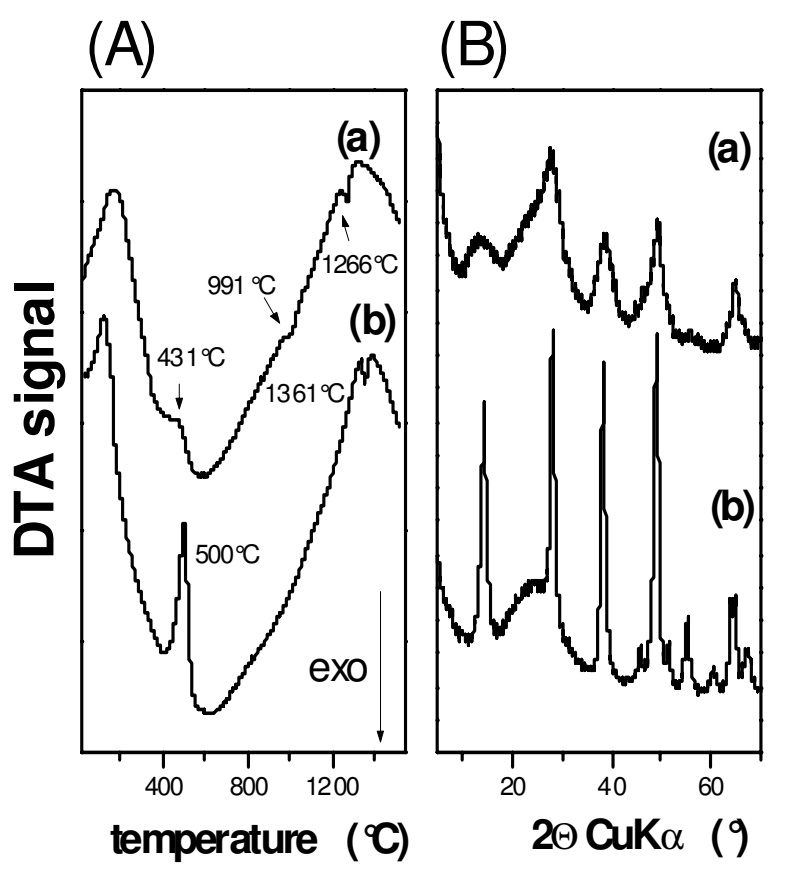

Figure 1. (A)-DSC scans and (B)-XRD patterns of as-dried gels. (a)- $P B M$, (b)- $B M$ gel. same 3:2 mullite composition (within the error span of EDX analysis) and similar specific surface area. However, in as-dried $P B M$ gel, alumina component is present as pseudoboehmite with particles about 10 nm size and in $B M$ sample as boehmite with $30-40 \mathrm{~nm}$ particle sizes (determined by TEM analyses). The phase composition and the crystallization pathway of the studied samples are given in Fig. 1. In $P B M$ gel small amount of spinel phase is also formed at $991^{\circ} \mathrm{C}$, therefore the gel is a combination of type II and type III precursors (Schneider's definition). Both phases; $\quad \gamma-\mathrm{Al}_{2} \mathrm{O}_{3}$, formed by the transformation of pseudoboehmite, and Al-Si spinel, crystallized from $\mathrm{SiO}_{2}$-rich amorphous matrix at $991^{\circ} \mathrm{C}$ ) react with the rest of amorphous silica forming orthorhombic mullite at $1266^{\circ} \mathrm{C}$. In $B M$ gel, $\gamma-\mathrm{Al}_{2} \mathrm{O}_{3}$ formed above $500^{\circ} \mathrm{C}$ reacts with amorphous silica forming orthorhombic mullite at $1361^{\circ} \mathrm{C}$; as shown on DTA scans in Fig. 1A. 


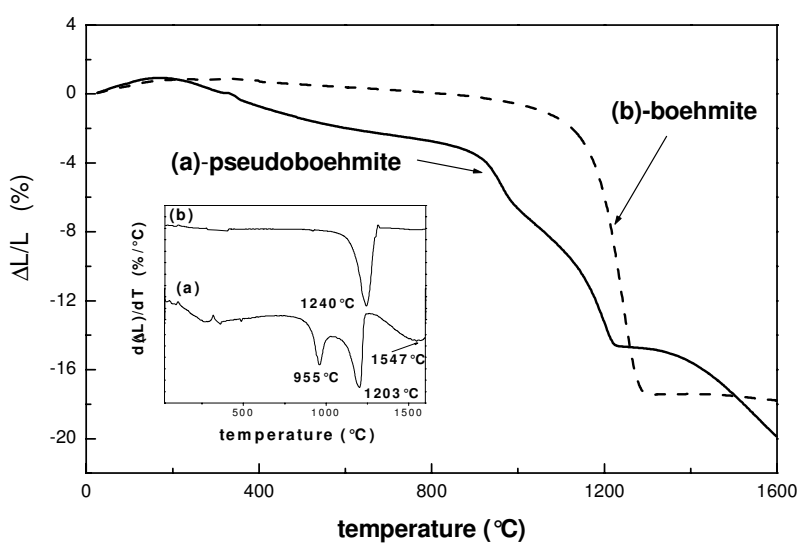

Figure 2. Dilatometric curves of studied sintered compacts. Derivativative curves are shown as insert.

The dilatometric and the corresponding derivative curves of compacts containing pseudoboehmite as a source of alumina (precursor $P B M$ ) show three step of densification (Fig. 2). On the contrary, the compact $B M$ shows only one large densification step between $1000-1300^{\circ} \mathrm{C}$. Comparing the mullite crystallization shown in Fig. 1A and dilatometric curves seen in Fig. 2, it can be concluded that with compacts containing in situ formed $\gamma-\mathrm{Al}_{2} \mathrm{O}_{3}$ covered with silica $(B M)$, the sintering is almost complete prior mullite crystallization, whereas in $P B M$ sample, mullite crystallization overlaps with the viscous flow sintering.

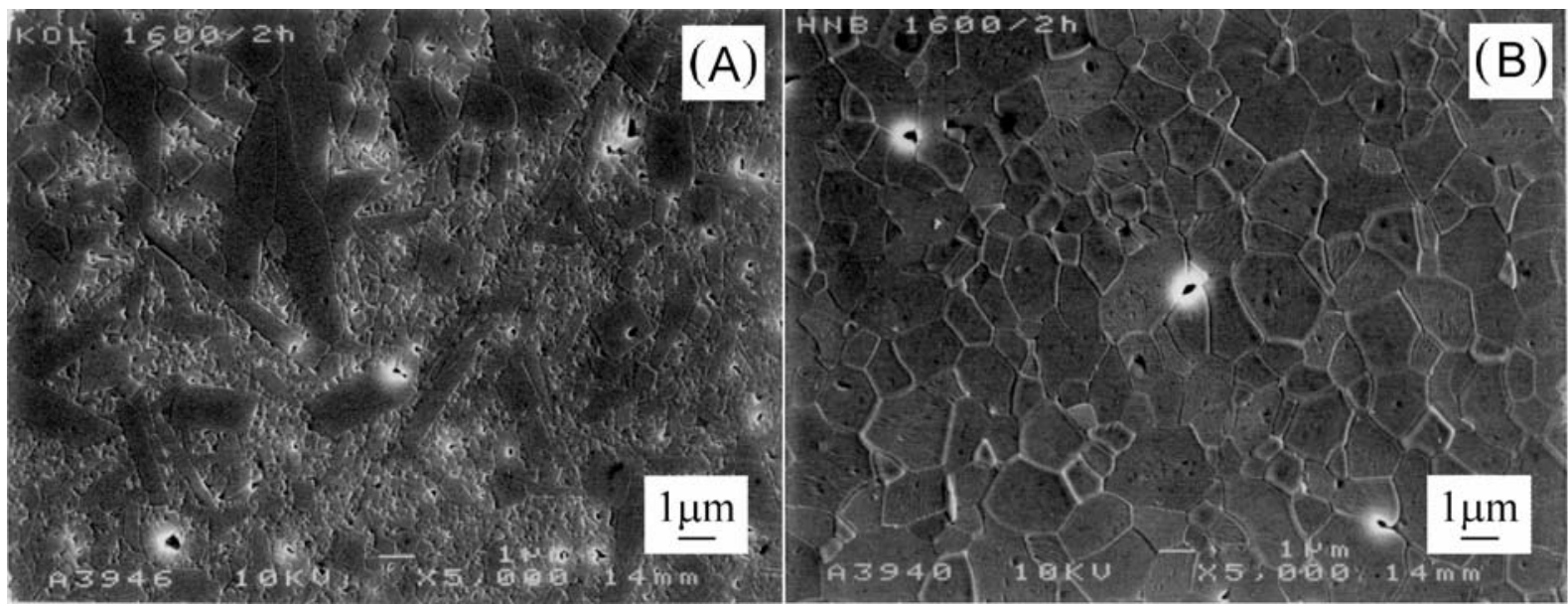

Figure 3. SEM micrographs of polished and thermally etched $\left(1500^{\circ} \mathrm{C}, 45 \mathrm{~min}\right)$ compacts sintered at $1600^{\circ} \mathrm{C}$ for $2 \mathrm{~h}$. (A)- $P B M$ sample; (B)- $B M$ sample

Fig. 3 shows representative SEM micrographs of polished and thermally etched pressureless sintered compacts at $1600^{\circ} \mathrm{C}$ for 2 hours. As shown, the resulting materials exhibit different microstructures. Sample PSM is composed of two types of grains: elongated crystals (with longer axis about 5-7 $\mu \mathrm{m}$ are embedded into a matrix of polyhedral much smaller grains (about $200 \mathrm{~nm}$ ). On the contrary, the mullite grains in specimen $B M$ are equiaxial with average sizes $1.3 \mu \mathrm{m}$, and with monomodal grain size distributions. According to Kanka and Schneider [7], the microstructure seen with specimen $B M$ is typical for liquid flow sintering, whereas a solid state sintering is supposed for the equaxial crystals. The microstructure evolution in mullite ceramics is largely dependent upon a number of factors (as in any sintering process), including the properties of precursors, calcination conditions, post-calcinations treatment and the green body forming methods. Except the mullite precursors, all other processes conditions were the same in our experiment. Because of that, the differences in the microstructure of the sintered bodies seen in Fig. 3 could be correlated with the precursor properties, moreover, with the crystalline form and particle size of alumina source in the precursors. It can be assumed, that the particle size of amorphous silica in the precursors varies in narrow range, and is smaller than $20 \mathrm{~nm}$, otherwise, according to Fahrenholtz et al. [8] cristobalite should be formed. No cristobalite was observed in any of the precursors. The presence of equiaxial grains has generally been associated with the absence of glassy phase and with high alumina compositions $[1,9,10]$, whereas stiff skeleton of interlinked elongated mullite crystals are associated with presence of liquid phase, and stoichiometric or low-alumina 
compositions [7]. We found by HRTEM analyses (not shown here) that both samples contain somewhat glassy phase and are of the same composition. Therefore, we suppose that not only the mentioned parameters, but also the mutually dependence of sintering and mullite crystallization are of the most important parameters which define the microstructure and properties of sintered bodies.

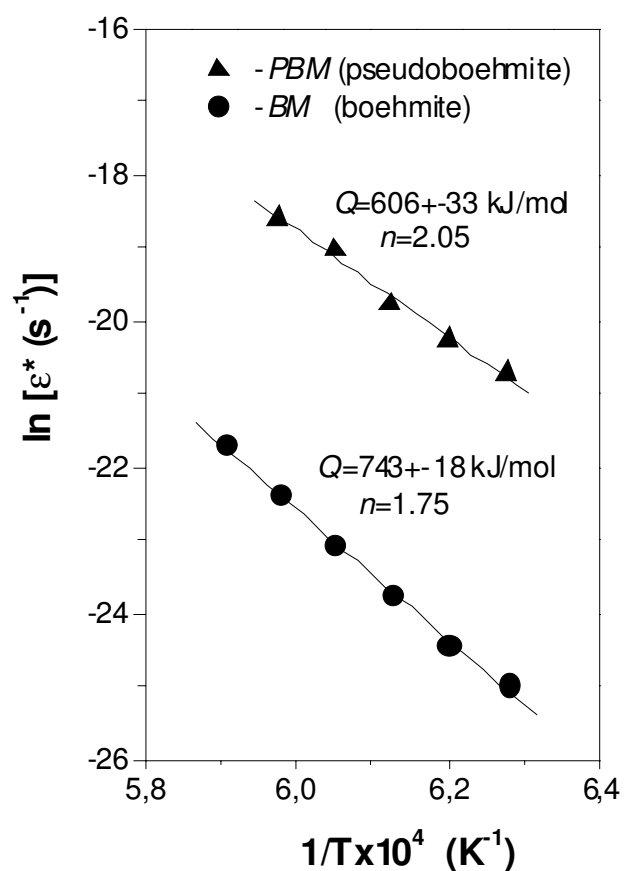

Figure 4. Strain rate vs. reciprocal temperature at stress of $100 \mathrm{MPa} ;(\boldsymbol{\Lambda}-$ $P B M ;-\bullet-B M$.
The creep behavior of sintered bodies is characterized by parameters $n, p$ and activation energy, $Q$, (Eq. (1)). Characteristic strain rate vs. $1 / \mathrm{T}$ plots at the stress of $100 \mathrm{MPa}$, from which the activation energies for creep are evaluated are shown in Fig. 4. The sample with bimodal grain size distributions ( $P B M$ sample) exhibited smaller activation energy and greater exponent $n$ ( $Q=606 \pm 33 \mathrm{~kJ} / \mathrm{mol}$ and $n=2.05$ ), than $B M$ sample with equiaxial grains $(Q=743 \pm 18 \mathrm{~kJ} / \mathrm{mol}$ and $n=1.75)$.

\section{Conclusion}

Clear differences were found in the microstructure and properties of diphasic precursor with pseudoboehmite as the alumina source in comparison to the precursor with boehmite as alumina source.

If pseudoboehmite is formed in a gel ( $P B M$ sample), specimen exhibited bimodal distributed grains. Elongated crystals are embedded into a matrix of polyhedral much smaller grains. This morphology is due to the overlapping of mullite crystallization and viscous flow sintering temperature.

On the contrary, if boehmite was used as alumina source ( $B M$ sample), the mullite formation is shifted above the sintering temperature, which enables formation of equiaxial mullite with mean particle size of $1.3 \mu \mathrm{m}$.

The sample with bimodally distributed grains exhibited the higher creep rate and smaller activation energy $(n=2.05 \pm 0.02$ and $Q=606 \pm 33 \mathrm{~kJ} / \mathrm{mol})$. The creep data for the sample with monomodally distributed particles of $1.3 \mu \mathrm{m}(n=1.75 \pm 0.02$ and $Q=742 \pm 18 \mathrm{~kJ} / \mathrm{mol})$ are approaching to values observed by other authors for diphasic gels.

\section{References}

[1] Schneider, H., Okada, K. and Pask, J. A., Mullite and Mullite Ceramics, Wiley, New York 1994.

[2] Lessing, P.A., Gordon, R.S., Mazniyashi K.S., J. Am. Ceram. Soc., 58 (1975), 149.

[3] Dokko, P.C., Pask, J.A. and Mazdiyasni, K.S., J. Am. Ceram. Soc., 60 (1977), 150.

[4] Hynes, A.P. and Doremus, R.H., J. Am. Ceram. Soc., 74 (1991), 2469.

[5] Tkalcec, E., Nass, R., Krajewski, T., Rein R. and Schmidt, H., J. Eur. Ceram. Soc., 18 (1998), 1089.

[6] Torrecillas, R., Calderón, J.M., Moya, J.S., Reece, M.J., Davies, C.K.L., Olagnon, C. and Fantozzi, G., J. Eur. Ceram. Soc., 19 (1999), 2519.

[7] Kanka, B. \& Schneider, H., J. Mat. Sci., 29 (1994), 1239.

[8] Fahrenholtz, W. G., Smith, D. M. and Cesarano III, J., J. Am. Ceram. Soc., 76 (1993), 433.

[9] Kara, F. and Little, J. A., J. Eur. Ceram. Soc., 16 (1996), 627.

[10] Kara, F., and Șener, O., J. Eur. Ceram. Soc., 21 (2001), 901. 